

\section{SOBRE OS AUTORES}

Eliana Paula Calegari I elianapaulac@gmail.com

Lattes: http://lattes.cnpq.br/2585905622643904

Mestre em Design pelo Programa de Pós-Graduação em Design com Ênfase em Design e Tecnologia pela Universidade Federal do Rio Grande do Sul (2013). Graduada em Desenho Industrial - Projeto de Produto (2011). Atualmente é doutoranda no Programa de Pós-Graduação em Design com Ênfase em Design e Tecnologia pela Universidade Federal do Rio Grande do Sul e professora do Ensino Básico, Técnico e Tecnológico do Instituto Federal de Educação, Ciência e Tecnologia de Rondônia. Atua como pesquisadora no Grupo de Estudos e Pesquisa em Inovação e Sustentabilidade da Amazônia - Gepisa, do Instituto Federal de Educação, Ciência e Tecnologia de Rondônia.

Hilton Albano Vieira Fagundes I hilton.arquiteto@gmail.com

Lattes: http://lattes.cnpq.br/0879838107418594

Graduado em Architektur und Stadtplanung - Arquitetura e Urbanismo - pela Universitaet Stuttgart, na Alemanha (1999) e mestrado em Engenharia Civil pela Universidade Federal do Rio Grande do Sul (2003). Graduado também em Ciências Econômicas pela Universidade Federal de Santa Maria (1984). Atua como professor na Universidade do Vale do Rio dos Sinos (Unisinos), no Centro Universitário Ritter dos Reis (Porto Alegre). Professor convidado do curso de especiallização em Construção pelo PPGEC-NORIE/UFRGS. Atua no curso de especialização em Construção Civil - Lato Sensu - na Unisinos e no curso de especialização em Design de Superfícies - Lato Sensu na Uniritter.

Jussara Smidt Porto I jussara.porto@ufrgs.br Lattes: http://lattes.cnpq.br/2870211672797838

Graduado em Comunicação Visual pela Universidade Federal de Santa Maria (1986). Especialista em Expressão Gráfica pela Universidade Federal do Rio Grande do Sul (1991). Especialista em Gestão Universitária pela Universidade Federal do Rio Grande do Sul (1995). É mestre em Design no Centro Universitário Ritter do Reis - Uniritter.

Mariana Schmidt de Oliveira I mari.schmidtoliveira@gmail.com

Lattes: http://lattes.cnpq.br/4951084547587449

Especialista em Marketing (2015) e mestre em Design (2017), ambos pela Universidade Federal do Rio Grande do Sul (UFRGS).

Luis Henrique Alves Candido I $00157156 @ u f r g s . b r$

Lattes: http://lattes.cnpq.br/5480346734351382

Graduado em Desenho Industrial (Projeto de Produto). Mestre e Doutor em Ciência e Tecnologia dos Materiais pelo Programa PPGE3M/UFRGS. Professor Adjunto no curso de design de produto (DEG/FA/UFRGS). Professor do Programa de Pós-Graduação em Design (PgDesign/UFRGS). Bolsista de Produtividade em Desenvolvimento Tecnológico e Extensão Inovadora (DT/CNPq). Pesquisador no Laboratório de Design e Seleção de Materiais (LDSM/UFRGS). 


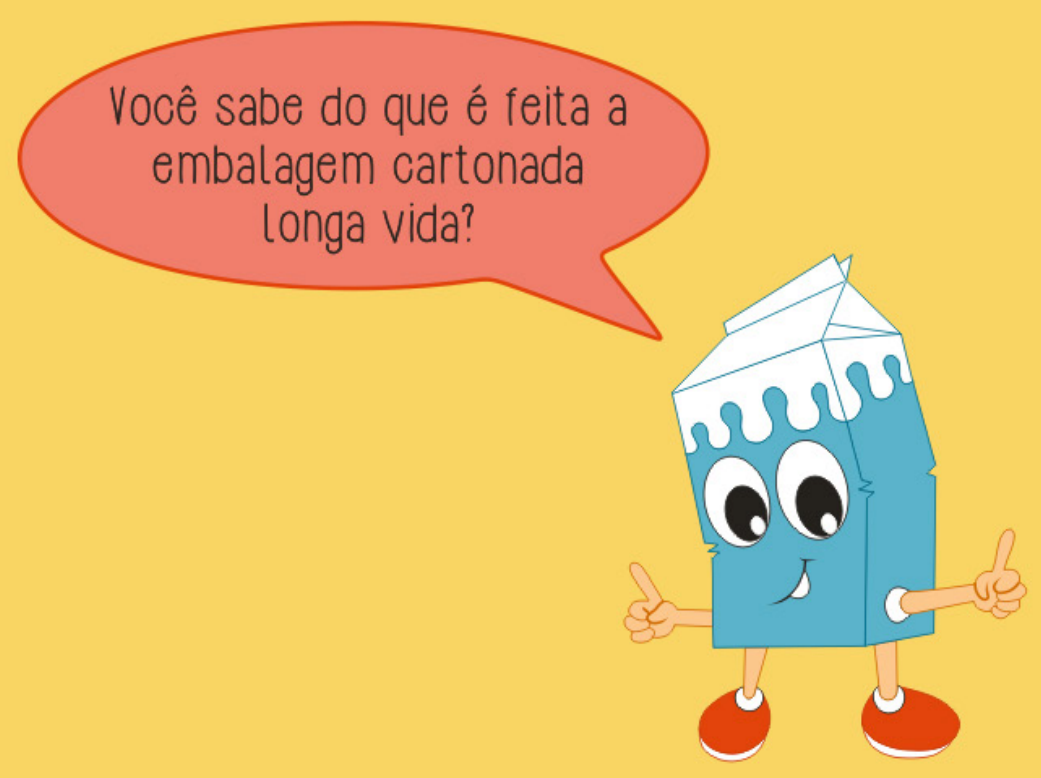

\title{
Desenvolvimento de livro infantil com enfoque na reutilização e na reciclagem da embalagem cartonada longa vida
}

\author{
Development children's book focus on reuse and \\ recycling of the long life carton packaging
}

Eliana Paula Calegari, Hilton Fagundes, Jussara Smidt Porto,

Mariana Schmidt, Luis Henrique Alves Cândido

\begin{abstract}
Resumo
O presente trabalho teve como proposta o desenvolvimento do livro infantil "A embalagem cartonada longa vida", que orienta o público-alvo, crianças de 5 a 8 anos de idade, sobre a destinação dessa embalagem após seu uso, com enfoque na reutilização e na reciclagem da embalagem. A construção do projeto gráfico do livro teve como elemento condutor, personagens que remetem a conteúdos diretamente ligados a estas embalagens, como leite e sucos. Buscou-se inovar no formato do livro bem como desenvolver um sistema de fechamento, e criar novos elementos para que as crianças possam interagir com o livro. Assim sendo, este trabalho visa despertar a reflexão sobre a reutilização e a reciclagem após o descarte desse tipo de embalagem a partir do design editorial de livros infantis buscando desenvolver um produto diferenciado.
\end{abstract}

Palavras-chave: Design editorial; Livro infantil; Embalagem cartonada longa vida.

\section{Abstract}

The present work had as its proposal the development of the children's book "A cartonada longa vida vida", which guides the target audience, children from 5 to 8 years old, on the destination of this packaging after its use, with a focus on reuse and recycling. In this sense, the construction of the graphic design of the book had as driving element, characters that refer to contents directly linked to these packages, such as milk and juices. It sought to innovate in the format of the book as well as develop a closure system, and create new elements so that the children can interact with the book. Therefore, this work aims to stimulate reflection on reuse and recycling after discarding this type of packaging from the editorial design of children's books seeking to develop a differentiated product. 


\section{INTRODUÇÃO}

Para a construção de uma sociedade crítica, o hábito da leitura deve ser estimulado desde a infância. Lourenço (2011) destaca que a vivência da leitura deve propiciar o desenvolvimento do pensamento organizado, capaz de levar o indivíduo a uma postura consciente, reflexiva e crítica frente à realidade social em que vive e atua. Conforme Halsam (2007) um livro preserva, anuncia, expõe e transmite conhecimento ao público, ao longo do tempo e do espaço.

Durante a infância desenvolvem-se os hábitos que serão levados com o indivíduo para toda a sua vida (MUNARI, 2008). Dessa forma, é extremamente importante estimular o gosto pelos livros desde os primeiros anos de vida das crianças. Segundo Romani (2011), no Brasil, a produção de livros infantis é considerada recente, sendo que sua expansão se concentrou nas últimas cinco décadas do século XX. O desenvolvimento do livro infantil está relacionado aos crescentes investimentos no setor editorial e às recentes tecnologias evidenciadas nas publicações a partir da década de 1990. Assim, novas formas de manipulação, que buscam testar os limites da percepção, são cada vez mais exploradas.

O livro infantil é utilizado como recurso pedagógico e pode ser um auxílio para compor, enriquecer e constituir a bagagem intelectual dos indivíduos. Além de auxiliar na alfabetização, o livro infantil tem o potencial de despertar a curiosidade, auxiliar no processo de captação e comparação de objetos, pessoas, lugares, e outros (ADAM, CALOMENO, 2012). Para Sawulski (2002) nas escolas, o livro infantil pode despertar o gosto pela leitura, pois, pode proporcionar fruição, alegria e encanto quando trabalhada de maneira significativa, além disso, pode desenvolver a imaginação, os sentimentos a emoção e a expressão através de uma aprendizagem prazerosa.

Neste viés, a preocupação ambiental é uma temática interessante para o desenvolvimento de livros infantis na medida em que busca informar sobre as consequências de nossas escolhas para o planeta em que vivemos. Neste contexto, tem-se gerado diversas iniciativas que buscam minimizar a poluição, o aquecimento global, a degradação dos recursos naturais e outros, como a reutilização e a reciclagem, que visam reduzir o desperdício de materiais e energia do planeta. A reutilização consiste no aumento do ciclo de vida dos materiais e produtos, e a reciclagem objetiva 
a transformação de materiais que já foram utilizados em matéria-prima para a produção de novos produtos. Desse modo, o objetivo deste trabalho é o desenvolvimento de um livro infantil visando à conscientização do público-alvo sobre a destinação da embalagem cartonada longa vida após o uso, abordando a reutilização e a reciclagem. Optou-se pela embalagem cartonada longa vida, pois, ela faz parte de muitos produtos consumidos pelas crianças, como leite, achocolatados e sucos.

\section{METODOLOGIA}

De acordo com Ambrose \& Harris (2011), o design é um processo que transforma um briefing em uma solução de design. Conforme os autores, a criatividade é importante e fundamental neste processo. No entanto, o desenvolvimento do design pode ser realizado de uma maneira controlada e direcionada pelo processo, canalizando a criatividade para a produção de uma solução prática e viável para o problema. Assim, o processo de design pode ser compreendido em sete etapas, conforme ilustra a Figura 1.

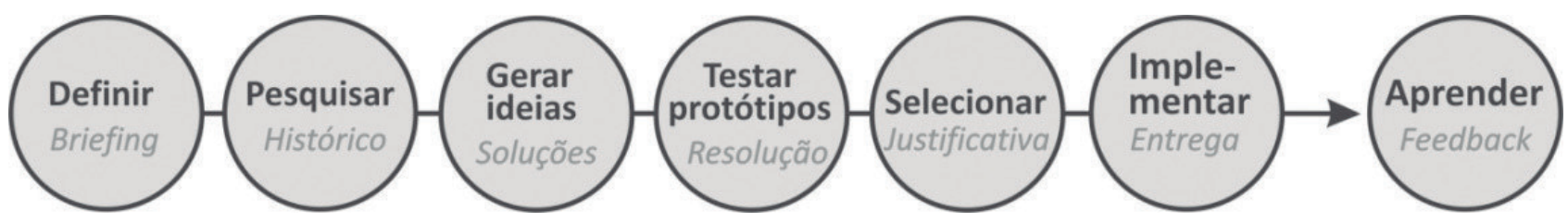

O processo metodológico inicia com a definição do problema e do públicoalvo, em que se busca compreender o problema e as suas possíveis restrições. Após, parte-se para a etapa de pesquisa, que consiste na

Figura 1: Etapas do processo de design. Fonte: Adaptado de Ambrose \& Harris (2011). coleta de informações acerca das variáveis envolvidas no problema, podendo realizar pesquisas sobre o histórico do objeto a ser projetado, pesquisas de usuário final, entrevistas de opiniões e pesquisas de campo. A partir do que foi constatado, parte-se para a geração de ideias levandose em consideração as motivações e as necessidades do público-alvo. Na etapa seguinte, testar protótipos, busca-se desenvolver e resolver as ideias geradas, e na fase de seleção, as soluções geradas são analisadas e seleciona-se a mais adequada de acordo com o objetivo do briefing. Finalmente, a solução selecionada é implementada, desenvolvendo-a até a finalização do projeto. Por fim, na etapa de aprendizado, busca-se compreender se a solução implementada atingiu os objetivos do projeto, através de feedback do público-alvo, com o intuito de averiguar melhorias 
que poderão ser realizadas no projeto. Dessa forma, tendo como base a metodologia de design de Ambrose \& Harris (2011) foi sistematizada a metodologia para este projeto, conforme pode ser visualizada na Figura 2.

\begin{tabular}{|c|c|c|c|c|c|}
\hline Definir & Pesquisar & Gerar ideias & Selecionar & $\begin{array}{c}\text { Testar } \\
\text { protótipos }\end{array}$ & Implementar \\
\hline $\begin{array}{l}\text {-Objetivo do } \\
\text { projeto } \\
\text {-Público-alvo }\end{array}$ & $\begin{array}{l}\text { - Análise de } \\
\text { similares } \\
\text { - A embala- } \\
\text { gem cartona- } \\
\text { da longa vida }\end{array}$ & $\begin{array}{l}\text { - Requisitos } \\
\text { de projeto } \\
\text { - Definição do } \\
\text { conceito } \\
\text { - Geração de } \\
\text { alternativas }\end{array}$ & $\begin{array}{l}\text { - Selecionar } \\
\text { alternativa } \\
\text { - Definições } \\
\text { formais }\end{array}$ & $\begin{array}{l}\text { - Teste da } \\
\text { montagem } \\
\text { do livro }\end{array}$ & $\begin{array}{l}\text { - Layout } \\
\text {-Impressão }\end{array}$ \\
\hline
\end{tabular}

Figura 2: Sistematização da metodologia para o desenvolvimento do livro. Fonte: Elaborada pelos autores.

Assim sendo, na primeira etapa da metodologia busca-se definir o objetivo do projeto e o público-alvo. Na sequência, realiza-se uma pesquisa em torno de livros infantis encontrados no mercado para a análise de similares. Além disso, nesta etapa, coleta-se informações sobre a embalagem cartonada longa vida, em relação aos materiais e processos de fabricação, reutilização e reciclagem. Na terceira etapa, gerar ideia, elenca-se os requisitos de projeto, definindo-se o conceito, e a partir disso, geram-se as alternativas. Na etapa seguinte, selecionar, selecionase a alternativa mais adequada com o escopo do projeto, e a partir disso, realizam-se as definições formais, como a escolha da tipografia, cores e outros. Na sequência, constroem-se e testam-se os protótipos.

\section{DESENVOLVIMENTO DO LIVRO}

\subsection{Definir}

O objetivo do projeto é desenvolver um livro infantil, para a faixaetária de 5 a 8 anos, sobre a reutilização e a reciclagem da embalagem cartonada longa vida. Segundo Arins (2015), os livros destinados às crianças de 5 a 8 anos apresentam pouco texto e muitas ilustrações, oferecendo ao público-alvo diversos estímulos visuais através de múltiplas cores, formatos e diagramações diferenciadas. Dessa forma, busca-se utilizar a predominância de ilustrações coloridas ao invés de textos, alternando texto em linhas e balões com falas de personagens. 


\subsection{Pesquisar}

\subsubsection{Análise de similares}

Foi realizada a análise de similares em cinco livros previamente selecionados: Malala, Assim Assado, A colcha de retalhos, 0 alvo e 0 Sapo Bocarrão, como podem ser visualizados na Figura 3: Os livros foram selecionados conforme a faixa etária do público-alvo, priorizando a seleção de livros com diferentes estilos, temáticas, tipografia, formatos e acabamentos.
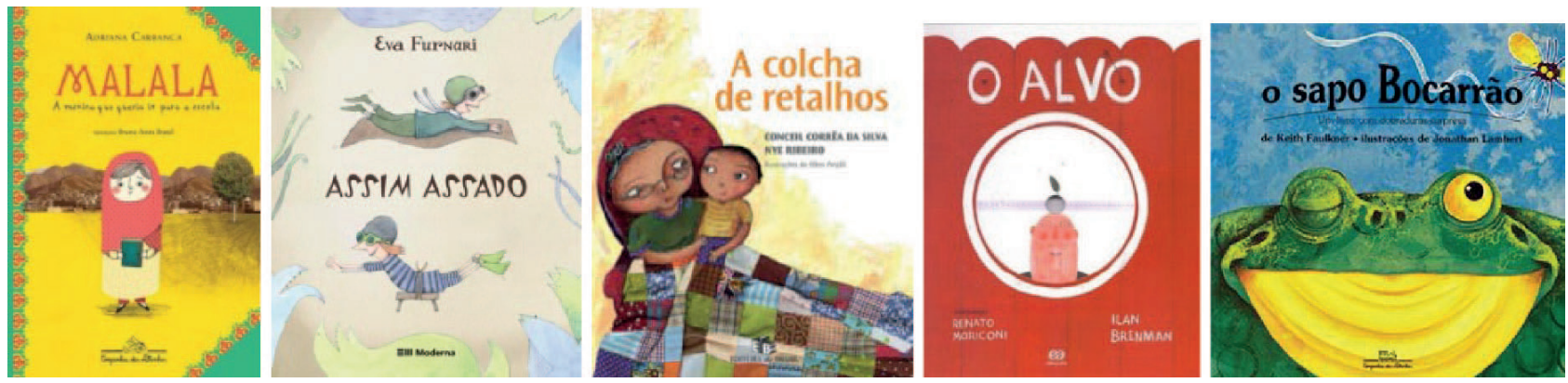

O livro "Malala: a menina que queria ir para a escola" possui o formato retrato, o que não é muito comum para livros infantis, há o uso de cores

Figura 3: Livros selecionados para análise de similares. Fonte: Elaborada pelos autores. vivas em todas as páginas do livro, é utilizado o fundo amarelo sobre o qual são aplicadas ilustrações coloridas. Em relação ao livro "Assim assado", o formato é tradicional, são utilizados tons claros para compor a paleta de cores que se restringe em tons de azul e verde, com fundo cinza. Sobre o livro "A colcha de retalhos", o formato e as ilustrações possuem estilo tradicional, em tons fortes e aquarelados, o fundo claro utilizado no livro salienta as ilustrações. O livro "Alvo" possui uma estética singular, a paleta de cores é restrita, vermelho e branco, possui recorte diferenciado na parte superior do livro, e o corte em formato circular na capa permite visualizar seu interior, que possui novo corte circular menor, que perpassa todas as páginas do livro, menos a contracapa. O livro "O sapo bocarão" possui formato quadrado, a paleta de cores restringe-se nas cores azul, verde e amarelo, em tons vibrantes, o interior do livro é composto por dobraduras. 


\subsubsection{A embalagem cartonada longa vida}

A embalagem cartonada longa vida foi projetada pela empresa sueca Tetra Pak. O primeiro lançamento da empresa foi criado por Ruben Rausing em 1951, e consistia em uma embalagem de forma tetraédrica construída de papelão parafinado. Em 1963, a empresa desenvolveu a embalagem tetra brik, já na forma das caixas de leite conhecidas nos dias de hoje, e, em 1968, o projeto foi aperfeiçoado e ocorreu o lançamento da tetra brik aseptic, na qual a tecnologia de acondicionamento permite um longo período de conservação, na temperatura ambiente, de alimentos líquidos sem o uso de conservantes (PELTIER, SAPORTA, 2009).

Conforme Pinatti (1999) o termo "longa vida" deve-se ao fato do alimento poder ser preservado em seu interior por um longo período, até 180 dias, sem precisar de refrigeração. Para essa proteção, as embalagens são fabricadas com três materiais: papel, polímero e alumínio, distribuídos em seis camadas. 0 papel corresponde a $75 \%$ do peso da embalagem, sendo produzido a partir de fibras de celulose da madeira de Pinus. O papel utilizado nas embalagens é o cartão duplex que possui uma camada branca, suas principais funções são oferecer suporte mecânico à embalagem e receber a impressão. Em relação ao polímero, é utilizado o polietileno de baixa densidade (PEBD) que corresponde a $20 \%$ em peso da embalagem. Esse polímero está presente em quatro camadas na embalagem, com a função de isolar o papel da umidade, impedir o contato do alumínio com o alimento e servir como elemento de adesão dos outros materiais presentes na estrutura (papel e alumínio). 0 alumínio corresponde a $5 \%$ em peso da embalagem e sua principal função é evitar a passagem de oxigênio, luz e microrganismos que possam entrar em contato com o alimento (BORGES, 2007).

A embalagem cartonada longa vida possui vantagens ambientais como a otimização do transporte, devido ao baixo peso, bom aproveitamento do volume, que é consequência da geometria da embalagem. Não necessita de refrigeração, assim, diminui o uso de energia e gases refrigeradores, além de diminuir a quantidade de alimentos desperdiçados por deterioração. No entanto, existem outras características que não são favoráveis ambientalmente. Por tratar-se de uma embalagem descartável de difícil processamento para a reciclagem, a embalagem representa um produto com alto potencial de geração de resíduos. Desse modo, pesquisas 
vêm buscando alternativas de beneficiamento pós-consumo desse tipo de embalagem. Cabe comentar que surgiram iniciativas de reciclagem tomadas pelas próprias empresas produtoras de embalagens que podem ser um destino menos danoso ambientalmente (ZORTEA, 2001).

\subsection{Gerar ideias}

Por meio da pesquisa bibliográfica e da análise de similares, foi obtido o embasamento para o desenvolvimento do livro. Com base nessa primeira etapa do projeto, foi possível listar os requisitos para o desenvolvimento prático do livro, levando em consideração a faixa etária do público-alvo. A Tabela 1 apresenta os requisitos de projeto, os quais fundamentam a etapa de conceituação, bem como as demais etapas de desenvolvimento do livro.

Tabela 1 - Requisitos de projeto.

\begin{tabular}{|c|l|}
\hline ATRIBUTOS DE PROJETO & \multicolumn{1}{c|}{ REQUISITO } \\
\hline Formato do livro & Formato diferenciado, versátil, fácil de manusear e transportar. \\
\hline Tipografia & $\begin{array}{c}\text { Fonte sem serifa, com uso de caracteres infantis e com boa diferenciação entre } \\
\text { os caracteres. }\end{array}$ \\
\hline Ilustração & $\begin{array}{c}\text { Ilustrações de estilo tradicional em cores marcantes, com uso de personagens } \\
\text { relacionados à temática da história. }\end{array}$ \\
\hline Texto & $\begin{array}{c}\text { Texto bem distribuído, com poucas linhas por página, alternando texto em linhas e } \\
\text { balões com falas de personagens. }\end{array}$ \\
\hline $\begin{array}{c}\text { Temática da história } \\
\text { mais interessante e fluída. }\end{array}$ & $\begin{array}{c}\text { Temática envolvendo a reutilização e a reciclagem da embalagem cartonada longa } \\
\text { vida, envolvendo elementos do cotidiano das crianças. }\end{array}$ \\
\hline $\begin{array}{c}\text { Promover a reflexão } \\
\text { sobre o descarte da } \\
\text { embalagem cartonada } \\
\text { longa vida }\end{array}$ & $\begin{array}{l}\text { Incorporar ao livro caminhos para o destino correto da embalagem cartonada longa } \\
\text { vida e estimular a reflexão sobre as ações tomadas no descarte destas } \\
\text { embalagens. }\end{array}$ \\
\hline
\end{tabular}


Figura 4: Painel com referências para a definição do conceito e geração de alternativas. Fonte: Elaborada pelos autores.

\subsubsection{Definição do conceito e geração de alternativas}

A formulação do conceito é baseada no levantamento e análise dos dados. A necessidade de gerar interesse do público infantil sobre o fim de vida da embalagem cartonada longa vida, principalmente, na destinação dessas embalagens após o uso, foi o ponto de partida para a definição do conceito do projeto. Para auxiliar a definição do conceito foi montado um painel sobre referências de livros e, da embalagem cartonada longa vida e de possibilidades de reutilização dessa embalagem, como pode ser visualizado na Figura 4.
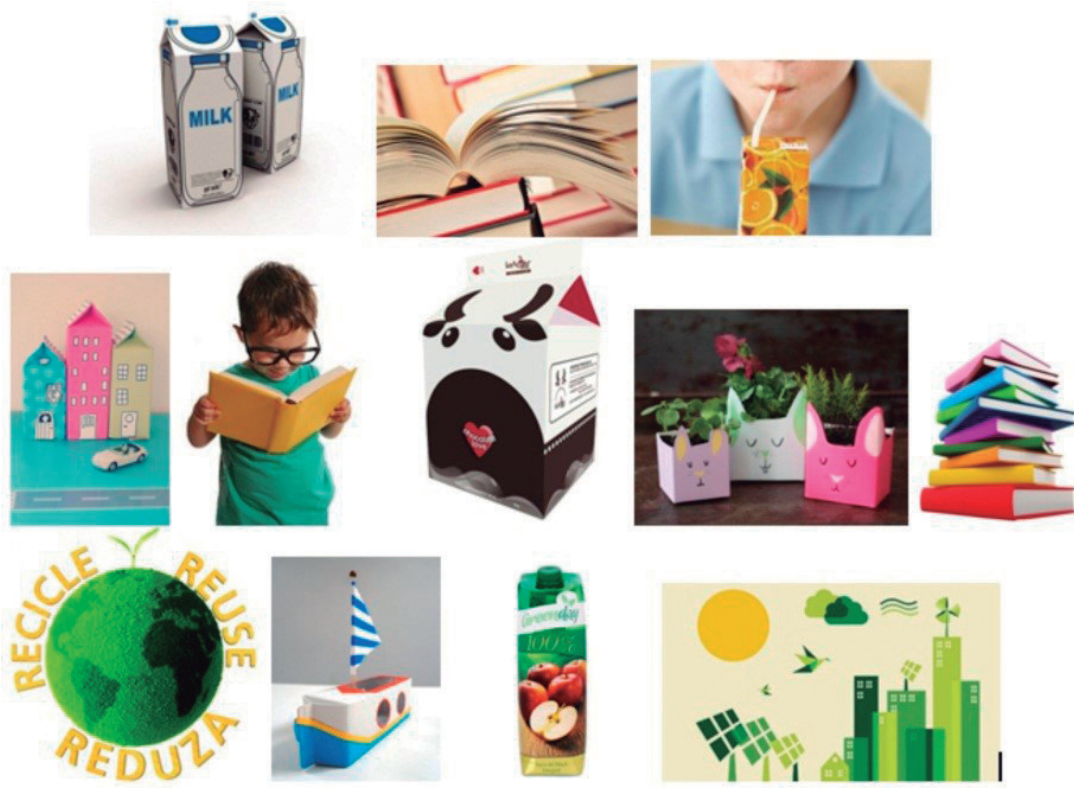

O levantamento de elementos para compor o painel, permitiu observar que as ações de ver, observar, ler e folhear um livro são fundamentais para a interação da criança com a obra. Além disso, percebeu-se que existem diversas maneiras de reutilizar as embalagens de leite e suco, que são alimentos corriqueiros do cotidiano das crianças, para transformá-las em brinquedos. Dessa forma, o livro pode conter elementos extras, que sugerem a reutilização das embalagens, que complementem o seu conteúdo. Assim, foram definidos os seguintes itens para o livro: com formato diferenciado, ou seja, de uma caixa de leite, de papel, de folhear ou não, com personagens, com fichas que sugerem a construção de brinquedos a partir da embalagem cartonada longa vida. Com isso, definiu-se o conceito como "uma embalagem com 
algo a mais", em que se busca desenvolver um livro que parte do formato da embalagem e que contenha elementos que sugerem a reutilização da embalagem cartonada longa vida. A partir do conceito e do painel, iniciouse a etapa de geração de alternativas. Foram geradas três alternativas formais, como podem ser visualizadas na Figura 5:

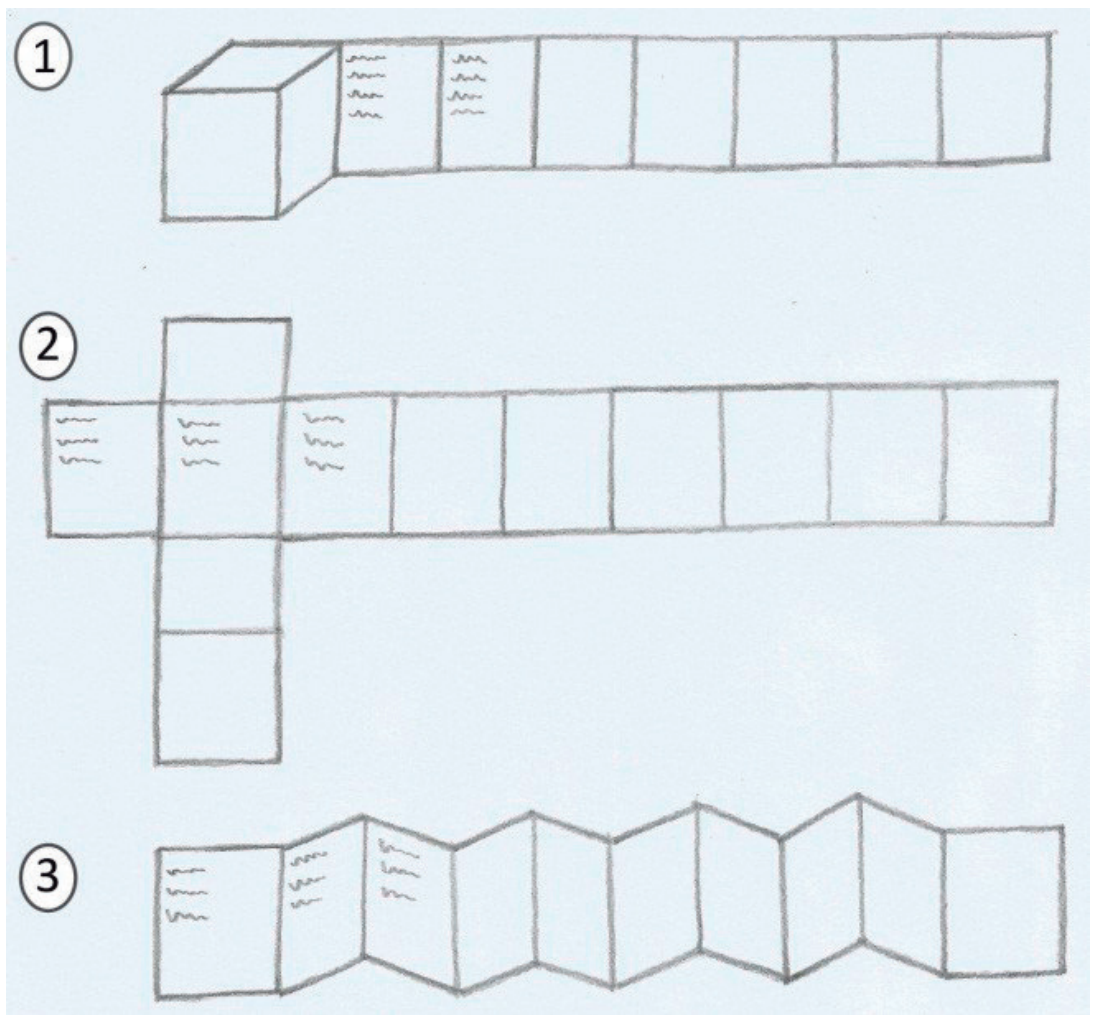

Na alternativa 1 as páginas do livro saem de dentro de uma caixa que simboliza a embalagem cartonada longa vida. Na alternativa 2 a própria caixa transforma-se em livro, e a alternativa 3, o livro possui o formato de "leque" e a capa e contracapa são rígidas e na proporção da embalagem cartonada longa vida de leite de $500 \mathrm{ml}$.

\subsubsection{Criação da história e definição do título}

Após a geração de alternativas, passou-se para a construção da história do livro. Para Cordeiro (1987) na literatura para a criança deve ser utilizado um vocabulário simplificado, evitando descrições longas, e utilizando imagens e situações visíveis, através do diálogo e da narração. Assim, é importante 
salientar que houve preocupação em criar uma história que estivesse de acordo com a faixa etária do público-alvo e alinhada com as características definidas no quadro de requisitos de projeto (Tabela 1). Com base nesses critérios, o roteiro da história seguiu os seguintes pontos:

- Descrever os materiais que compõem as embalagens e explicitar de onde eles são extraídos.

- Apontar caminhos com o que pode ser feito após o uso das embalagens.

- Informar sobre a destinação na lixeira correta.

- Apontar de que forma a embalagem cartonada pode ser reutilizada a partir da criação de brinquedos.

- Abordar a importância da reciclagem da embalagem cartonada longa vida.

- Para a criação do título foi utilizado o principal elemento da história do livro que é a embalagem, dessa forma, o título foi definido como "A Embalagem Cartonada Longa Vida".

\subsection{Selecionar}

Em relação ao formato do livro, a alternativa 3 (Figura 5), mostra-se a mais alinhada com os propósitos do projeto, principalmente, no que tange a incorporação do livro no cotidiano das crianças, a facilidade de manuseio, e a viabilidade de produção. Em relação à seleção tipográfica, baseou-se no uso de fonte com caracteres infantis e com boa diferenciação entre os caracteres. Com base nesses parâmetros, foi selecionada a fonte Hipsterish Font Normal para as páginas internas do livro e a fonte From Cartoon Blocks para a capa, como mostra a Figura 6.

\section{Hipsterish Font Normal}

$\Lambda$ embalagem cartonada longa vida

From Cartoon Blocks

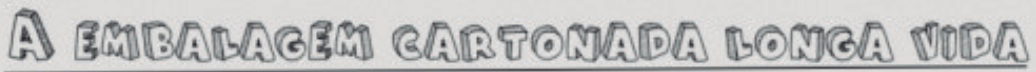

Figura 6: Fontes para o projeto gráfico das páginas internas e do título do livro. 
Optou-se por definir uma paleta contendo quatro cores principais para ser utilizada nos elementos principais e como cores de fundo no interior do livro e para as fichas, e uma paleta de sete cores para a capa e contracapa, como pode ser visualizado na Figura 7 e 8.
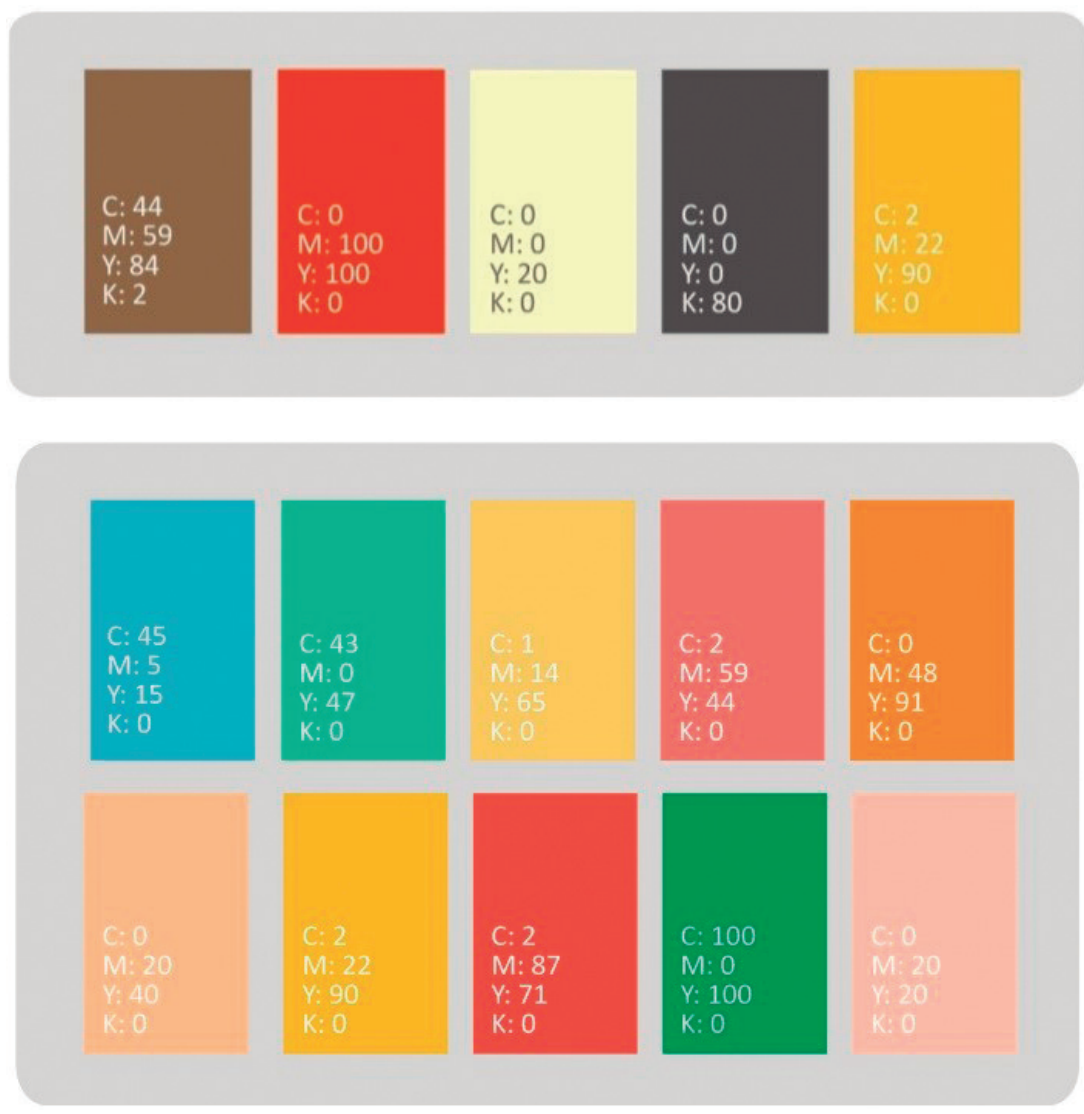

\section{Figura 8: Paleta de cores das páginas internas do livro em CMYK.}

Figura 7: Paleta de cores da capa e contracapa em CMYK.

A diagramação de um livro envolve as decisões sobre a posição exata de todos os elementos da página, assim, nesse projeto foi utilizada a diagramação em página única. 0 processo de definição da diagramação foi iniciado por meio de um esquema à mão livre. Nesse esquema foi prevista a distribuição do texto e das ilustrações em cada página. 0 texto foi posicionado na página com alinhamento na esquerda, e a ilustração foi posicionada na parte inferior da folha alinhada a direita e em algumas páginas, devido ao tamanho da ilustração foram centralizadas na página. A diagramação foi realizada a partir da organização editorial ilustrada na Figura 9. 

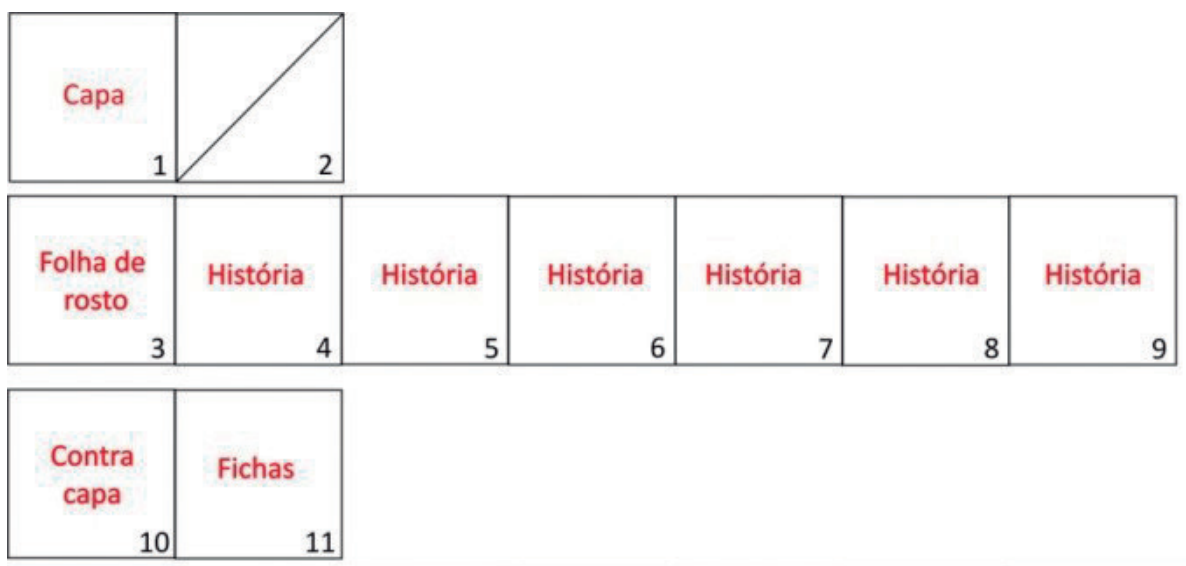

\begin{tabular}{|c|c|c|c|c|c|c|c|c|c|}
\hline História & História & História & História & História & História & História & História & $\begin{array}{l}\text { Nota dos } \\
\text { autores }\end{array}$ & $\begin{array}{l}\text { Nota dos } \\
\text { autores }\end{array}$ \\
\hline 12 & 13 & 14 & 15 & 16 & 17 & 19 & 20 & 21 & 22 \\
\hline
\end{tabular}

Figura 9: Organização editorial do livro.

O livro possui personagens, que contam a história, estes foram criados seguindo estilo tradicional e em cores marcantes, inspirados na embalagem cartonada longa vida dos produtos alimentícios que fazem parte do cotidiano das crianças, como o leite e os sucos. O leite foi representado pelo personagem da vaca e da caixa de leite, e os sucos pelos personagens de frutas, como o morango, o abacaxi e a Iaranja. Inicialmente foram criados sketches, como ilustra a Figura 10 e na sequência foram finalizados em software gráfico, resultando nas imagens da Figura 11.
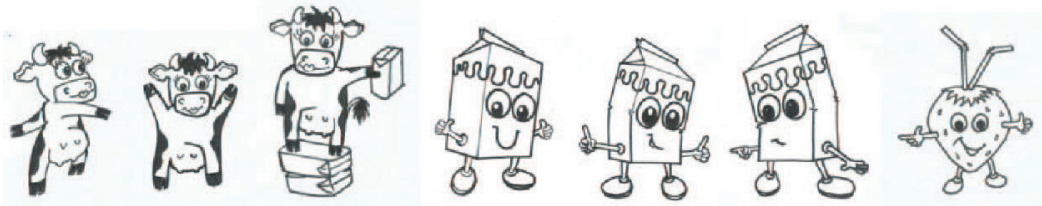

Figura 10: Sketches dos personagens do livro.
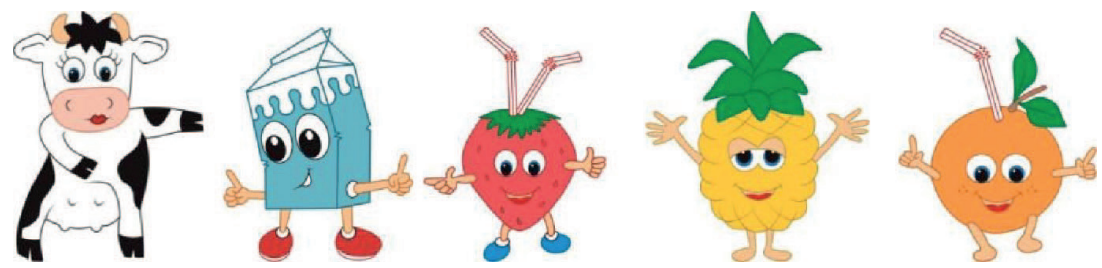

Figura 11: Finalização dos personagens do livro: vaca, caixa de leite, morango, abacaxi e laranja. 
A criação da capa foi desenvolvida a partir do formato do livro, que segue as proporções de uma caixa de leite de $500 \mathrm{ml}$, na dimensão de $11 \mathrm{~cm}$ de altura por $9 \mathrm{~cm}$ de largura. Na capa foi desenvolvida uma ilustração da vaca e na contracapa a representação posterior da vaca, para atribuir ideia de continuidade, como pode ser observada na Figura 12.
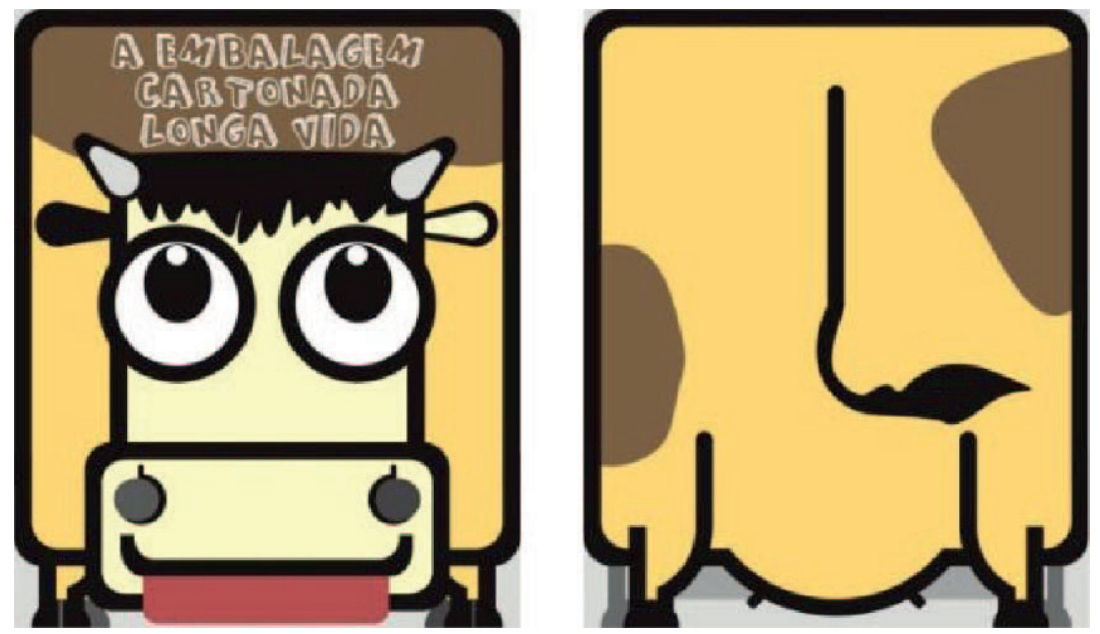

Figura 12: Capa e contracapa.

As fichas, anexadas no livro, sugerem brinquedos que podem ser construídos a partir da reutilização de embalagem cartonada longa vida. Foram criadas quatro fichas na dimensão de $5 \mathrm{~cm}$ de largura e $7 \mathrm{~cm}$ de altura, que possuem as seguintes sugestões de brinquedos: fantoche, carteira, cofrinho, trator, conforme ilustra a Figura 13. Para verificar as instruções de confecção dos brinquedos, é preciso acessar o código QRCode da ficha, que irá direcionar o usuário ao site que possui as instruções. Estas fichas são alocadas atrás da contracapa do livro.
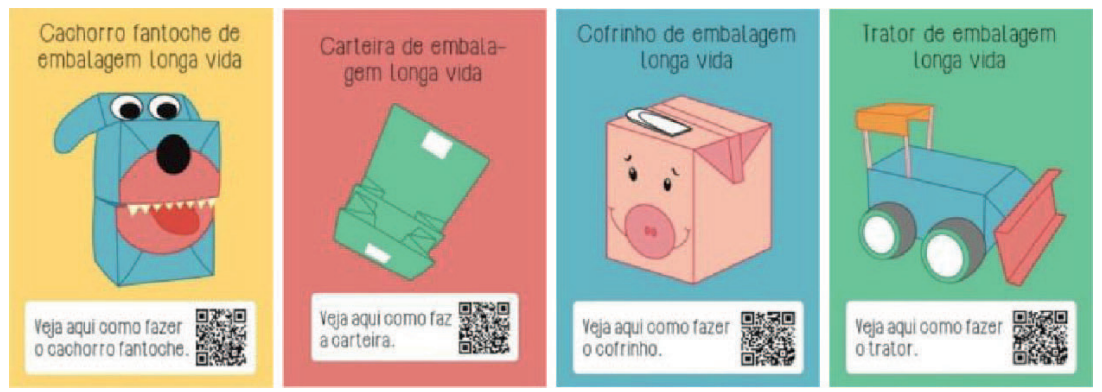

Figura 13: Fichas que auxiliam a construção de brinquedos a partir da reutilização da embalagem cartonada longa vida. 
A escolha do papel foi feita cuidadosamente, visto que ele irá compor a forma física do livro. Dessa forma, para as páginas internas do livro foi escolhido o papel reciclado 120g. Foi selecionado o papel reciclado por envolver a temática trabalhada no livro. Para a capa e contracapa foi selecionado o papel paraná $400 \mathrm{~g}$ revestido com papel reciclado $120 \mathrm{~g}$ com acabamento plastificado fosco. A encadernação foi realizada através de colagem, e a impressão digital foi feita em equipamento Konica Minolta bizhub Press c6000.

\subsection{Testar protótipos}

A montagem do livro foi testada com a construção de protótipos, como pode ser visto nas Figura 14. Confeccionou-se um protótipo do livro em formato de "leque" e a capa e contracapa rígidas para estruturar o livro, seguindo as proporções da embalagem cartonada longa vida de leite de $500 \mathrm{ml}$.

Figura 14: Protótipo utilizado para testar a montagem do livro no formato de "leque".

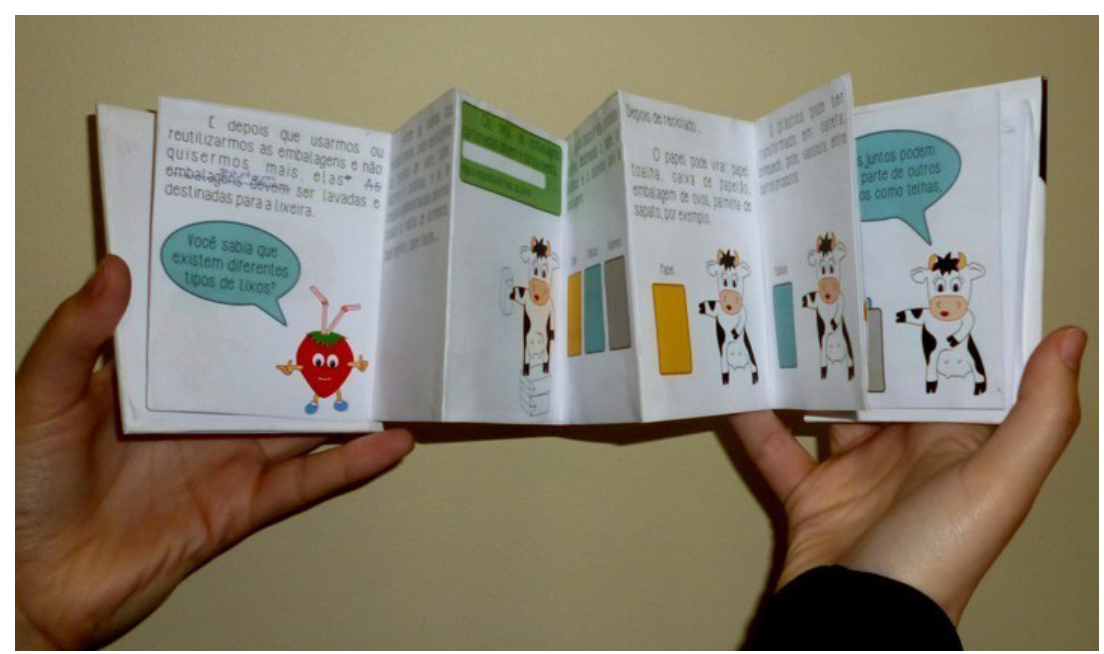

Para o fechamento do livro optou-se por utilizar uma aba localizada na parte interna da contracapa e é encaixada na capa, essa aba representa a língua da vaca. A aba de fechamento do livro é um prolongamento de um envelope utilizado para guardar as fichas referentes às sugestões de construção de brinquedos com as embalagens após o uso, como pode ser observado na Figura 16. 

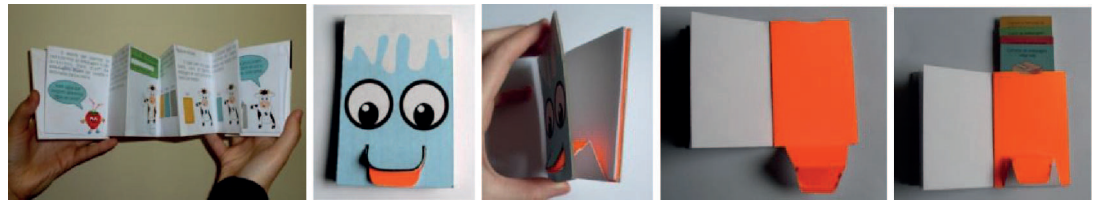

Figura 15: Fechamento do livro e envelope para alocar as fichas.

\subsubsection{Layout}

Com base na definição de todos os elementos já apresentados, foi desenvolvido o layout definitivo das páginas de narrativa do livro. Este layout pode ser visualizado na Figura 16. Devido ao formato de "leque", as páginas foram impressas frente e verso, dessa forma, a sequencia de leitura é realizada a partir de um lado do livro e continua do outro lado, para isso é preciso virar o livro, em que há uma indicação na última página da primeira parte.

Figura 16: Layout do livro.

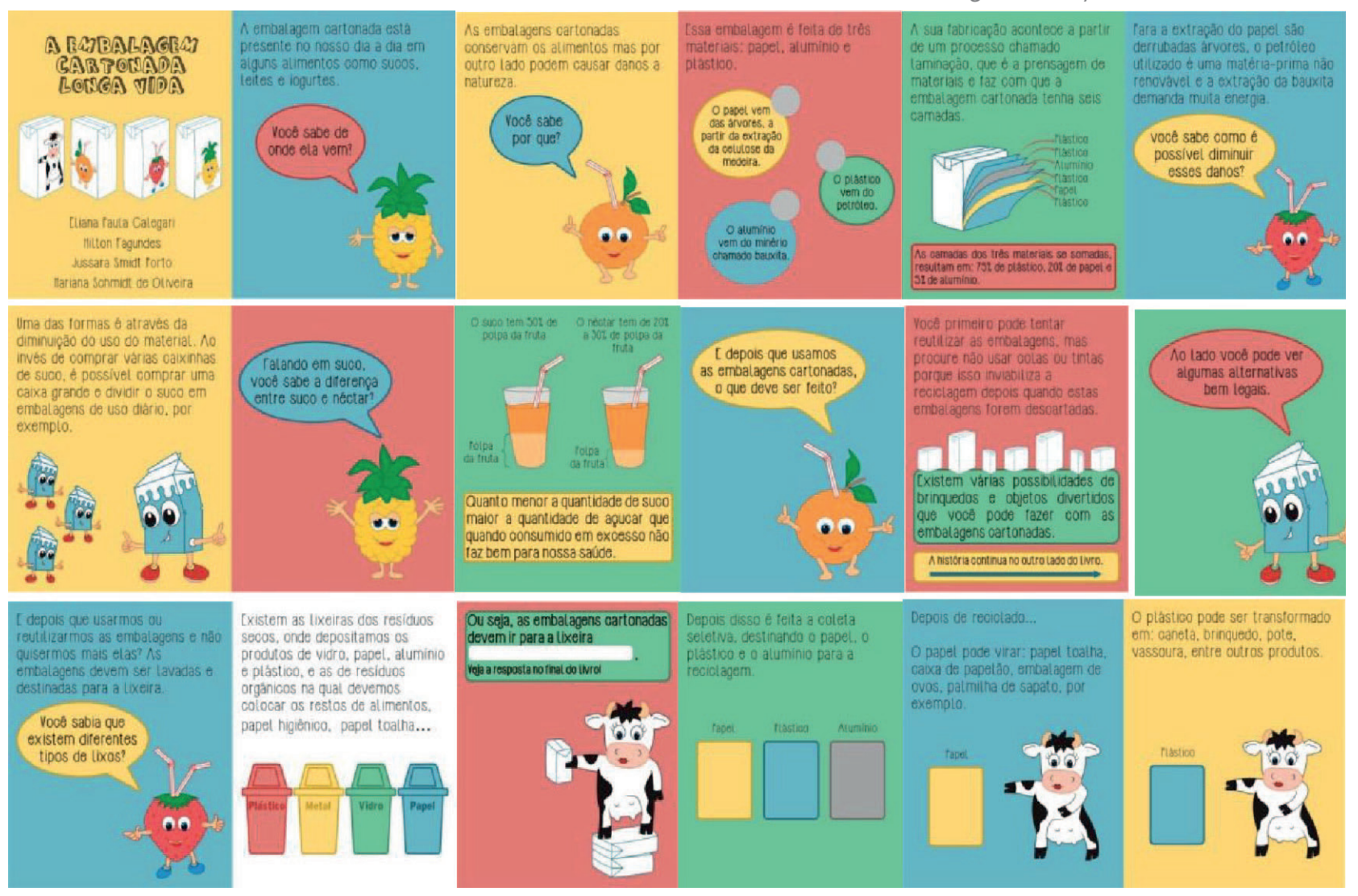


Figura 18: Detalhes e uso do livro: A) Vista superior, B) Detalhe da abertura, C), D) e E) Abertura, F) Páginas internas, G) Fichas.
A última etapa da implementação do livro consistiu na construção de um protótipo, que é apresentado na Figura 17. Nessa figura, podese observar a capa, com a ilustração da face da vaca e o detalhe do fechamento representado pela "língua", na contracapa visualizase a ilustração da parte posterior da vaca, a qual remete a ideia de continuidade.
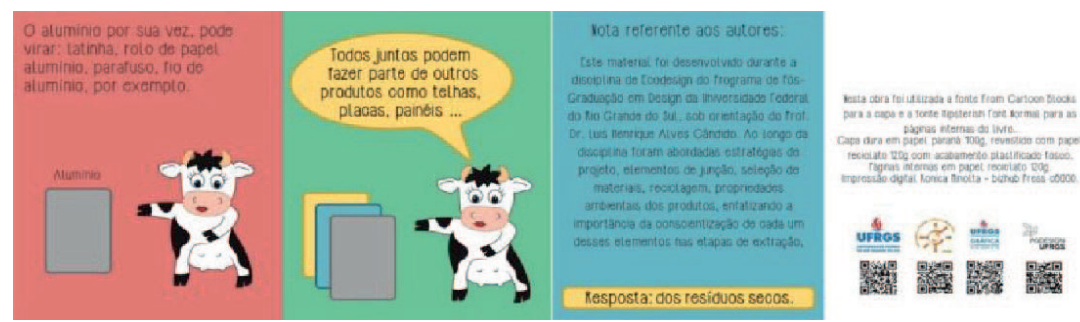

Figura 17: Livro impresso.

Na Figura 18, pode-se observar como é realizada a abertura do livro, os detalhes das páginas internas e o espaço para locação das fichas na contracapa.
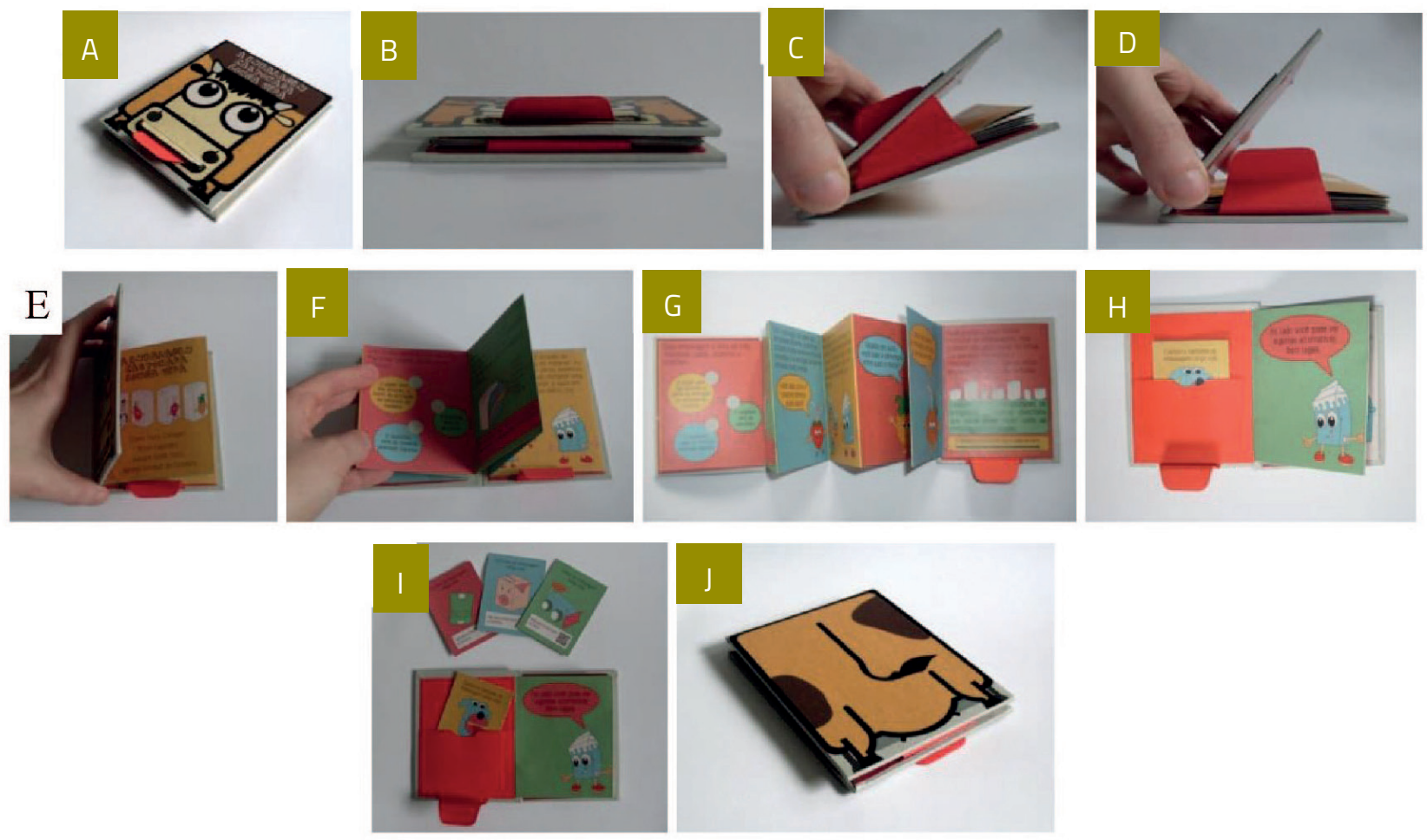


\section{CONSIDERAÇÕES FINAIS}

Iniciativas que visam à reflexão e a conscientização em torno de nossas ações sobre o meio ambiente são cada vez mais importantes no cenário de degradação ambiental em que vivemos. Neste sentido, este trabalho visou o desenvolvimento de um livro infantil com a proposta de despertar a reflexão de crianças, na faixa etária de 5 a 8 anos, sobre a destinação da embalagem cartonada longa vida após o consumo.

Para o desenvolvimento do livro infantil, foi utilizada a metodologia proposta por Ambrose \& Harris (2011) e seguindo os atributos do projeto gráfico de livros. Inicialmente, foi realizada uma pesquisa na literatura sobre a temática principal do livro, os materiais, a reciclagem e a reutilização da embalagem cartonada longa vida. A partir disso, iniciou-se o processo de desenvolvimento do livro, que procurou levar em consideração o público-alvo e as características do projeto gráfico de livros infantis fundamentadas por autores da área.

Como resultado, obteve-se um livro infantil diferenciado, versátil e fácil de manusear e transportar, principalmente pelo formato, e condizente com a proposta de possuir elementos em que a criança possa interagir com o livro, como foi o caso das fichas, que o torna mais atrativo e interativo. Cabe comentar que o livro "A embalagem cartonada longa vida" pode ser utilizado tanto em escolas como em casa, pois possui caráter informativo e educativo de fácil compreensão. 


\section{REFERÊNCIAS}

ADAM, D. L.; CALOMENO, C. Metodologia para adaptação de conteúdo editorial imagético para deficientes visuais. InfoDesign, São Paulo, v. 9, n. 3, p. 201-215, 2012

AMBROSE, G; HARRIS, P. Design thinking. Porto Alegre: Bookman, 2011

ARINS, R. D. A. Redesign de livro infantil com projeto gráfico adequado para faixa etária de 9 a 12 anos. XVI Congresso de Ciências da Comunicação na Região Sul, Joinville, Santa Catarina, 2015

BORGES, D. G. Aproveitamento de embalagens cartonadas em compósito de polietileno de baixa densidade. Mestrado (Dissertação). Programa de Pós-Graduação em Engenharia da Escola Politécnica da Universidade de São Paulo.

CORDEIRO, X. L. Da invenção da imprensa ao livro infantil: um enfoque editorial. Faculdade de Biblioteconomia e Documentação Faculdades Integradas Teresa D'Ávilla, São Paulo, 1987.

LOURENÇO, D. A. Tipografia para livro de literatura infantil: desenvolvimento de um guia com recomendações tipográficas para designers. Dissertação (Mestrado). Programa de PósGraduação em Design da Universidade Federal do Paraná, Curitiba, 2011.

PELTIER, F; SAPORTA, H. Design sustentável: caminhos virtuosos. São Paulo: Editora Senac 2009.

PINATTI, A. E. O design de embalagem de consumo e o meio ambiente - O sistema ecológicoambiental: ecodesign. Tese (Doutorado). Programa de Pós-Graduação da Faculdade de Arquitetura e Urbanismo da Universidade de São Paulo, São Paulo, 1999.

ROMANI, E. Design do livro-objeto infantil. Dissertação (Mestrado). Programa de Pós-Graduação em Arquitetura e Urbanismo da Universidade de São Paulo, 2011.

SAWULSKI, V. Fruição e/ou aprendizagem através da Literatura Infantil na escola. Disponível em: <http:/www.cce.ufsc.Br/neitezel/literaturainfantil/verena>. Acesso em: novembro de 2015.

ZORTEA, R. B. Viabilidade econômica e tecnológica para a reciclagem das embalagens cartonadas longa vida pós-consumo de Porto Alegre. Dissertação (Mestrado). Programa de Pós-Graduação em Administração da Escola de Administração da Universidade Federal do Rio Grande do Sul, Porto Alegre, 2001. 